\section{ACE in the hole}

\section{By Tim Fulmer, Senior Writer}

American and Japanese researchers may have found a way to boost the efficacy of marketed angiotensin-converting enzyme inhibitors by combining them with inhibitors of chymase, ${ }^{1}$ a protease that is abundant in cardiac tissue. The researchers now want to partner with a company to test the dual inhibitor strategy in a clinical trial to treat hypertension.

Angiotensin-converting enzyme (ACE) inhibitors prevent ACE from converting angiotensin I to angiotensin II. By doing so, the molecules counteract multiple downstream effects of excessive angiotensin II, including high blood pressure as well as cardiac hypertrophy and fibrosis that can lead to heart failure.

However, chronic use of the drugs can lead to a phenomenon known as ACE inhibitor escape, in which angiotensin II levels do not fall back to normal despite substantial ACE inhibition. For example, a study in 2000 by researchers in Spain showed that about $50 \%$ of congestive heart failure (CHF) patients had some form of ACE inhibitor escape. Escape was associated with poor prognosis. ${ }^{2}$

When inhibitor escape occurs, clinicians may combine ACE inhibitors with angiotensin receptor blockers (ARBs), which prevent angiotensin II from binding its receptor, angiotensin II type 1 receptor (AGTR1). The rationale is that ACE inhibition should block some production of angiotensin II while ARBs will prevent the remaining angiotensin II from binding and activating AGTR1.

Despite the biochemical rationale, the combination therapy has not always panned out in clinical trials when compared with either agent alone. Indeed, the side-effect profile of the combination has often outweighed any potential benefits. ${ }^{3}$

Thus, many research groups have been searching for an ACEindependent angiotensin II production pathway to explain how ACE inhibitor escape occurs and to determine how to counteract the phenomenon.

Ahsan Husain, professor of medicine at the Emory University School of Medicine, and colleagues think they might have an answer. The team previously focused on production of angiotensin II in mammalian hearts, in which they found that chymase localized to cardiac mast cells and catalyzed the formation of angiotensin II independent of ACE. ${ }^{4-7}$
That finding suggested chymase might generate angiotensin II even in the presence of an ACE inhibitor and thus be at least partly responsible for ACE inhibitor escape. If so, inhibiting chymase could prevent escape and boost the efficacy of ACE inhibitors.

To test that hypothesis, the group has now looked at an ACE inhibitor together with a chymase inhibitor in post-myocardial infarction (MI) hamsters. Compared with an ACE inhibitor, the combination improved left ventricle function, decreased adverse cardiac remodeling and improved survival.

Additional studies in mice revealed a mechanism by which chronic ACE inhibition boosted chymase activity in the heart, contributing to ACE inhibitor escape. The missing link was bradykinin, a peptide that normally acts to dilate blood vessels. In addition to ACE inhibitors' intended effect of blocking the formation of angiotensin II from angiotensin I, they also protect bradykinin from degradation.

As a result, bradykinin is able to bind its receptor on cardiac mast cells, triggering the release of chymase, which is then available to generate angiotensin II even in the presence of an ACE inhibitor (see Figure 1, "Preventing ACE inhibitor escape").

The authors thus proposed that "the cardiac benefits of ACE inhibition may be better realized by combining it with simultaneous chymase inhibition."

Results were published in The Journal of Clinical Investigation. The study was headed by Husain, Louis Dell'Italia, professor of medicine at The University of Alabama at Birmingham, and Hidenori Urata, professor of cardiovascular diseases at the Fukuoka University Chikushi Hospital.

\section{ACE up the sleeve}

The JCI paper "gives some of the strongest evidence yet that marketed ACE inhibitors cannot by themselves totally suppress production of angiotensin II to treat heart failure," said Carlos Ferrario, professor of medicine at the Wake Forest University School of Medicine and a researcher in the Hypertension and Vascular Research Center.

"The animal studies are quite solid, and the clear next step is longterm clinical trials combining ACE inhibitors with chymase inhibitors to treat some form of cardiovascular disease," he told SciBX.

This year, Ferrario plans to present data that will provide additional support for the JCI paper. "In cardiac atrial tissue resected from heart failure patients, we found that chymase is responsible for a significant amount of angiotensin II production from angiotensin-(1-12), suggesting that supplementing ACE inhibitors with chymase inhibitors may indeed be a better way to go than ACE inhibitors alone or ACE inhibitor/ARB combinations," he said.

Ferrario plans to report those results at the Federation of American Societies for Experimental Biology meeting this month.

In parallel with their work on chymase, Ferrario and colleagues also are focusing on angiotensin-(1-7), an endogenous peptide that 


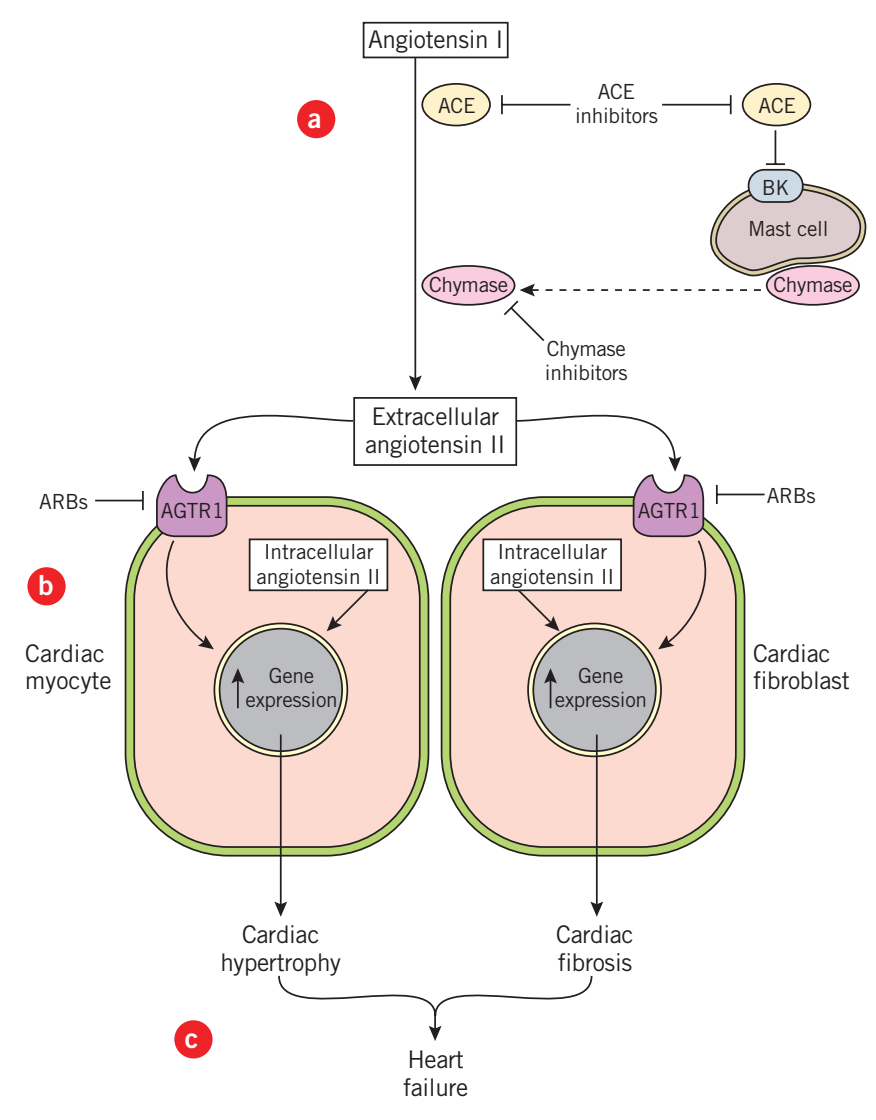

counteracts the effects of angiotensin II. Increasing levels of angiotensin-(1-7), as opposed to reducing levels of angiotensin II, could slow or prevent progression of heart failure without the side effects associated with ACE inhibitors, such as coughing and dizziness.

\section{Finding a partner}

Corresponding author Husain told SciBX he wants to study the chymase/ACE inhibitor dual therapy in patients.

Although the JCI paper provides support for looking at the dual therapy in heart failure, "I believe the initial trial ought to be in hypertension," he said. "Compared with heart failure trials, dosing regimens are easier to determine in hypertension trials and imaging is typically not required. That could translate into a simpler trial design and overall lower cost. If the dual therapy is safe and efficacious in hypertension, it would then make sense to study it next in heart failure trials."

To help fund either trial, "we're hoping to arrange a partnership with a biotech or pharma that has an active chymase inhibitor program," Husain added.

His best bet might be Teijin Pharma Ltd., which provided the chymase inhibitor used in the JCI paper.

According to the U.S. Patent and Trademark Office, Teijin has applied for a U.S. patent that claims "a method for reducing cardiac dysfunction following myocardial infarction comprising administering to a subject in need thereof an effective amount of a chymase inhibitor and an ACE inhibitor."

Husain told SciBX that Urata, one of the paper's lead authors, is
Figure 1. Preventing ACE inhibitor escape. Results in The Journal of Clinical Investigation suggest that chymase inhibitors could boost the efficacy of angiotensin-converting enzyme (ACE) inhibitors by preventing a phenomenon known as ACE inhibitor escape.

ACE inhibitors target ACE to block production of angiotensin II [a], which prevents activation of the angiotensin II type 1 receptor (AGTR1) on cardiac cells [b] and downstream expression of multiple genes that contribute to heart failure [c].

ACE inhibitor escape occurs when the drugs induce increased extracellular levels of bradykinin (BK), which binds its receptor on cardiac mast cells and triggers release of chymase. Chymase is a protease that generates angiotensin II even when ACE is blocked. Thus, chymase inhibitors in combination with ACE inhibitors should block angiotensin II production better than ACE inhibitors alone.

Along with ACE inhibitors, angiotensin receptor blockers (ARBs), which target AGTR1 on cardiac and vascular cells, are marketed to treat hypertension and heart failure. a consultant to the company. However, "we have no formal arrangements to continue working with Teijin moving forward," Husain said.

Teijin did not respond to requests for comment.

Johnson \& Johnson has a few publications on phosphonic acidderived chymase inhibitors ${ }^{8-10}$ and also owns at least one patent covering them.

In one of the company's papers, the chymase inhibitor RWJ355871 (JNJ-10311795) showed efficacy in animal models of asthma and pulmonary inflammation. However, J\&J spokesperson Ernie Knewitz told SciBX that the company "is not actively working in the chymase area at this time."

\section{Inside attack}

Whereas the JCI paper suggests that chymase inhibitors could help ACE inhibitors block extracellular levels of angiotensin II, a group in Texas is taking a different approach, focusing on intracellular angiotensin II.

Rajesh Kumar and colleagues at the Texas A\&M Health Science Center have shown in animal models that angiotensin II production inside cardiac cells is aberrantly upregulated during hyperglycemia. ${ }^{11,12}$

"We believe that intracellular angiotensin II is the main driver of chronic conditions, such as heart failure, at least under diabetogenic conditions. It may thus be necessary to block production of intracellular angiotensin II to prevent downstream expression of genes that can trigger cardiac hypertrophy and fibrosis," said Kumar, who is an assistant professor of internal medicine. 


\section{ANALYSIS}

Kumar told SciBX he is collaborating with an undisclosed company to develop therapeutic strategies that target pathways of intracellular angiotensin II production to treat heart failure.

Fulmer, T. SciBX 3(15); doi:10.1038/scibx.2010.454

Published online April 15, 2010

\section{REFERENCES}

1. Wei, C.-C. et al. J. Clin. Invest.; published online March 24, 2010; doi:10.1172/JCl39345

Contact: Hidenori Urata, Fukuoka University Chikushi Hospital,

Fukuoka, Japan

e-mail: uratah@fukuoka-u.ac.jp

Contact: Louis Dell'Italia, The University of Alabama at Birmingham,

Birmingham, Ala.

e-mail: dellltalia@physiology.uab.edu

Contact: Ahsan Husain, Emory University School of Medicine,

Atlanta, Ga.

e-mail: ahusai2@emory.edu

2. Roig, E. et al. Eur. Heart J. 21, 53-57 (2000)
3. Mann, J. et al. Lancet $\mathbf{3 7 2}, 547-553$ (2008)

4. Urata, H. et al. Circ. Res. 66, 883-890 (1990)

5. Urata, H. et al. J. Biol. Chem. 265, 22348-22357 (1990)

6. Dell'Italia, L. et al. Curr. Opin. Cardiol. 17, 374-379 (2002)

7. Urata, H. et al. J. Clin. Invest. 91, 1269-1281 (1993)

8. Maryanoff, B. et al. Am. J. Respir. Crit. Care Med. 181, 247-253 (2010)

9. Greco, M. et al. J. Med. Chem. 50, 1727-1730 (2007)

10. de Garavilla, L. et al. J. Biol. Chem. 280, 18001-18007 (2005)

11. Kumar, R. et al. Curr. Hypertens. Rep. 11, 104-110 (2009)

12. Kumar, R. et al. Trends Endocrinol. Metab. 18, 208-214 (2007)

\section{COMPANIES AND INSTITUTIONS MENTIONED}

Emory University School of Medicine, Atlanta, Ga.

Fukuoka University Chikushi Hospital, Fukuoka, Japan

Johnson \& Johnson (NYSE:JNJ), New Brunswick, N.J.

Teijin Pharma Ltd., Tokyo, Japan

Texas A\&M Health Science Center, Temple, Texas

The University of Alabama at Birmingham, Birmingham, Ala.

U.S. Patent and Trademark Office, Alexandria, Va.

Wake Forest University School of Medicine, Winston-Salem, N.C. 